\title{
Host Range and Genetic Relatedness of Colletotrichum acutatum Isolates from Fruit Crops and Leatherleaf Fern in Florida
}

\author{
S. J. MacKenzie, N. A. Peres, M. P. Barquero, L. F. Arauz, and L. W. Timmer
}

First and second authors: University of Florida, Department of Plant Pathology, Gulf Coast Research and Education Center, Wimauma 33598; third and fourth authors: University of Costa Rica, San Jose, Costa Rica; and fifth author: University of Florida, Department of Plant Pathology, Citrus Research and Education Center, Lake Alfred 33850. Accepted for publication 20 January 2009.

\begin{abstract}
MacKenzie, S. J., Peres, N. A., Barquero, M. P., Arauz, L. F., and Timmer, L. W. 2009. Host range and genetic relatedness of Colletotrichum acutatum isolates from fruit crops and leatherleaf fern in Florida. Phytopathology 99:620-631.

Isolates of Colletotrichum acutatum were collected from anthracnoseaffected strawberry, leatherleaf fern, and Key lime; ripe-rot-affected blueberry; and postbloom fruit drop (PFD)-affected sweet orange in Florida. Additional isolates from ripe-rot-affected blueberry were collected from Georgia and North Carolina and from anthracnose-affected leatherleaf fern in Costa Rica. Pathogenicity tests on blueberry and strawberry fruit; foliage of Key lime, leatherleaf fern, and strawberry; and citrus flowers showed that isolates were highly pathogenic to their host of origin. Isolates were not pathogenic on foliage of heterologous hosts; however, several nonhomologous isolates were mildly or moderately pathogenic to citrus flowers and blueberry isolates were pathogenic to

strawberry fruit. Based on sequence data from the internal transcribed spacer (ITS) 1-5.8S rRNA-ITS2 region of the rDNA repeat, the glutaraldehyde-3-phosphate dehydrogenase intron $2(G 3 P D)$, and the glutamine synthase intron $2(G S)$, isolates from the same host were identical or very similar to each other and distinct from those isolated from other hosts. Isolates from leatherleaf fern in Florida were the only exception. Among these isolates, there were two distinct $G 3 P D$ and $G S$ sequences that occurred in three of four possible combinations. Only one of these combinations occurred in Costa Rica. Although maximum parsimony trees constructed from genomic regions individually displayed little or no homoplasy, there was a lack of concordance among genealogies that was consistent with a history of recombination. This lack of concordance was particularly evident within a clade containing PFD, Key lime, and leatherleaf fern isolates. Overall, the data indicated that it is unlikely that a pathogenic strain from one of the hosts examined would move to another of these hosts and produce an epidemic.
\end{abstract}

Colletotrichum acutatum J. H. Simmonds is a globally distributed species that causes disease on a wide range of plant hosts, including fruit and vegetable crops, pine, and leatherleaf fern $(26,33)$. Simmonds (31) first described the species in a study of Colletotrichum spp. that caused fruit rots in Australia, where it was isolated commonly from fruit of papaya, strawberry, and solanaceous crops. C. acutatum is distinguished from other Colletotrichum spp. by production of ellipsoid conidia, slow growth in culture, and a pink to chromogenic red colony color. An isolate from papaya from northern Australia was established recently as the epitype of this species (40) because Simmonds (31) never properly established a type specimen. C. acutatum sensu lato (s.l.) includes strains displaying some morphological and genetic variation from the original species description of Simmonds (21). To aid classification of C. acutatum (s.l.) strains, molecular markers have been used to give strains a genetic group designation $(12,17$, $21,33)$. Some of the genetic groups are also differentiable using morphological characters (21). The isolates composing groups are consistent across multiple studies, although the groups have been described using different terminologies. For example, one has been described as group C (17), group A (21), subgroup I (12), or group A3 (33) in different studies. Except as noted, we use the terminology of Guerber et al. (17) to describe groups in this report. For a cross reference of group designations from different studies, refer to Sreenivasaprasad and Talhinhas (33). Four to eight $C$. acutatum groups have been identified using nucleic acid

Corresponding author: S. J. MacKenzie; E-mail address: sjmac@ufl.edu

doi:10.1094/PHYTO-99-5-0620

(c) 2009 The American Phytopathological Society sequence data $(12,17,21,33)$. Differences in the number of groups identified depended on the number and variability of isolates evaluated and the mutation rate of the loci used for phylogenetic analysis. Some groups probably define a recombining population that is genetically isolated from other groups and, thus, fit the criteria of true biological species. For example, isolates from group $\mathrm{C}$ produce the teleomorph of $C$. acutatum, Glomerella acutata, when paired with other group $\mathrm{C}$ isolates and isolates from only one other genetic group, J4 $(16,17)$. Although they formed fertile perithecia when paired with $\mathrm{J} 4$ isolates, the genetic distance between group $\mathrm{C}$ and $\mathrm{J} 4$ isolates suggests that they do not recombine in nature (17). A teleomorph has also been described from group $\mathrm{F}$ isolates (21). Other groups have not been shown to produce a teleomorph, suggesting that strains from these groups reproduce vegetatively and that the genetic groups comprise similar isolates at the termini of strictly clonal lineages. There could still be limited recombination between groups or among strains within genetic groups for which no teleomorph has been described. Analysis of the congruence of gene trees from multiple loci would provide evidence for or against recombination at some point in the history of strains from these groups (15).

Generally, within C. acutatum, strains do not appear to be limited to a single host, but there may be exceptions. Groups are typically composed of isolates from multiple hosts (33). Often, a strain can cause disease on a host other than its host of origin, given that genetically indistinguishable or very similar isolates within the same group attack the alternative host. For example, based on rDNA internal transcribed spacer (ITS) and $\beta$-tubulin 2 nucleotide sequences and arbitrarily primed polymerase chain reaction (ap-PCR) banding patterns, isolates from olive and anemone and a clonal population from strawberry were identical or highly 
similar to one another and isolates from both olive and anemone were pathogenic to strawberry $(14,37)$. Pink-pigmented isolates from apple and peach also were cross pathogenic and displayed identical or similar AT-rich DNA and ap-PCR banding patterns $(3,13)$. Isolates from postbloom fruit drop (PFD)-affected citrus and anthracnose-affected Key lime are very closely related to one another and are included in group J (17). However, PFD isolates did not cause Key lime anthracnose and Key lime anthracnose isolates caused less PFD than isolates from PFD-affected sweet orange $(1,25)$. Thus, it appears that, within this group, strains may have a more limited host range, and consistent differences in DNA markers between isolates responsible for these diseases supports this (25).

Isolates from the same host, such as those from apple, citrus, lupine, olive, pecan, pine, and strawberry, can also be found in more than one group $(17,36,37)$. The occurrence of genetically variable strains on the same host suggests that multiple lineages contribute to epidemics of the same disease. However, in many studies where isolate groups were determined, only the host of origin is reported and not the disease or symptoms caused. It is conceivable that, if pathogenicity tests had been conducted and disease symptoms described, some isolates would not have been classified as pathogens or differences in the symptoms caused by isolates from different groups would be distinguishable. When large samples of isolates that cause PFD on citrus and anthracnose of Key lime, lupine, olive, and anemone at multiple locations were examined, nearly all of the isolates responsible for each disease were genetically uniform $(14,25,36,37)$. There were two distinct populations that were shown to produce anthracnose lesions on strawberry fruit or foliage and one of the populations was genetically uniform throughout the world (6). The occurrence of one or a few broadly distributed genotypes at multiple geographic locations does not support the idea that multiple genetic lineages contribute to disease epidemics caused by $C$. acutatum and indicates that strains of this species are host specific. However, specificity may not always be limited to one host, as demonstrated by the homogenous population that causes disease on strawberry, olive, and anemone (14,37). Because diseases are often associated with a single strain of $C$. acutatum or strains from a limited number of genetic groups, it is important that genetic information such as that provided by group designations be used to describe $C$. acutatum when referring to a disease.

In central Florida, important diseases caused by $C$. acutatum include anthracnose of strawberry (19) and leatherleaf fern (34), PFD of citrus (42), as well as Key lime anthracnose, which is a problem in home garden plantings. Blueberry ripe rot is another important disease caused by $C$. acutatum, but it is not clear if it is caused by $C$. acutatum or by $C$. gloeosporioides in central Florida (32). Crops grown in central Florida display the broad range of symptoms caused by $C$. acutatum. On strawberry, $C$. acutatum causes lesions on fruit and petiole tissues, flower blight, and plants may be stunted or killed if roots are infected (11). On leatherleaf fern, the fungus blights immature fronds and, on Key lime, it blights immature leaf tissue, stems, and flowers (26). PFD symptoms include necrosis of petal tissue, abscission of fruitlets, and persistence of the calyxes after fruit abscission (42). On blueberry, $C$. acutatum typically infects fruit when green and the fruit rots after it matures (26). It may also blight leaves or twigs of this host.

Previous studies indicate that $C$. acutatum strains responsible for PFD and anthracnose of Key lime, leatherleaf fern, and strawberry in Florida belong to at least two previously identified $C$. acutatum groups (17). Isolates from citrus with PFD in the Americas belonged to group J (17) and were all highly similar to one another (25). Groups $\mathrm{C}$ and $\mathrm{F}$ also contained citrus isolates (17) but the isolates were from New Zealand and no citrus disease caused by $C$. acutatum has been reported from that country. Key lime anthracnose isolates and two isolates from leatherleaf fern collected in Florida were also in group $\mathrm{J}$ (17). Sequences from numerous Key lime isolates from throughout the Americas have been characterized and all of the isolates were very similar, yet distinct from PFD isolates (25). Leatherleaf fern anthracnose was reported first in Costa Rica and it is believed that it was introduced into Florida from that country (24). Molecular analyses using ap-PCR marker and ITS2 sequence data showed that leatherleaf fern isolates from Costa Rica were distinct from strawberry isolates in that country and that leatherleaf fern isolates were distinct from a citrus isolate based on ap-PCR markers but not on ITS2 sequence data (30). It is not clear whether the Costa Rican leatherleaf fern isolates are the same as isolates from Florida because sequence data at a common locus is not available for comparison. Strawberry isolates from around the world can be found in groups C, D, F, and J (17). The vast majority of strawberry isolates are from a group referred to as the CA-clonal group by Denoyes-Rothan et al. (6). The CA-clonal group is synonymous with group D (33). Denoyes-Rothan et al. (6) also described a more heterogeneous CA-variable group of isolates. Most of these isolates produced a pink chromogenic color in culture, whereas CA-clonal isolates appeared orange (6). In Florida, strawberry isolates show little genetic variation and colony color is orange, indicating that they belong to the CA-clonal group (43). Characterized $C$. acutatum isolates from blueberry occur in group C $(17,33)$ and a recently described group, A9, from Australia (44). No blueberry isolates from Florida have been characterized. If $C$. acutatum is responsible for blueberry ripe rot in Florida, the number of $C$. acutatum groups most commonly associated with disease on citrus, Key lime, strawberry, leatherleaf fern, and blueberry in this region would likely increase by at least one.

In the present study, $C$. acutatum isolates were obtained from PFD-affected citrus; anthracnose-affected Key lime, strawberry, and leatherleaf fern; and ripe rot-affected blueberry in Florida or neighboring states. The pathogenicity of these isolates was determined on each of the five hosts and the genetic relatedness of isolates was determined from sequence data at three loci. Concordance of gene genealogies was examined to determine if there was a history of recombination among isolates from the different hosts. Isolates from leatherleaf fern in Costa Rica were also compared with those from Florida. The study provides information on the genetic relatedness of $C$. acutatum isolates from cultivated crops in Florida and their potential to attack other hosts.

\section{MATERIALS AND METHODS}

Isolates and isolation procedures. Isolates of $C$. acutatum were recovered from strawberry, leatherleaf fern, and Key lime affected by anthracnose; ripe rot-affected blueberry; and sweet orange flowers affected by PFD. Isolates and data collected from each isolate are listed in Table 1. To obtain most of the isolates, tissues were surface sterilized using $0.6 \%$ sodium hypochlorite for $1 \mathrm{~min}$, rinsed three times in sterile water, and plated on a general isolation (GI) medium (19.5 g of potato dextrose agar [PDA] $9.5 \mathrm{~g}$ of agar, $0.1 \mathrm{~g}$ of streptomycin, and $0.25 \mathrm{~g}$ of ampicillin per liter of water). To obtain blueberry isolates, fruit with no disease symptoms were collected from two fields in Dover, FL or purchased in the grocery store where the fruit was grown in Florida, Georgia, or North Carolina. The fruit was surface disinfested and placed on a wire mesh in a humid chamber at $22^{\circ} \mathrm{C}$. Ripe-rot symptoms developed after 1 week and isolations were made from the affected fruit. Most of the isolates recovered from fruit in Florida were C. gloeosporioides, but one isolate of $C$. acutatum was obtained from a field in Dover. $C$. acutatum isolates were recovered commonly from fruit grown in North Carolina and Georgia. All isolates were single spored. Three isolates from each host were selected for pathogenicity experiments and for phylogenetic analysis. Blueberry isolates came from Florida, Georgia, and North Carolina; all other isolates came from central 
or south Florida. Gene sequences or restriction fragment length polymorphism (RFLP) banding patterns from amplified sequences were obtained for additional leatherleaf fern isolates from Florida and Costa Rica to compare strains present in these two countries. Due to quarantine restrictions, the leatherleaf fern isolates remained in Costa Rica, where DNA was extracted and shipped to the United States. Seven isolates were deposited in the American Type Culture Collection (ATCC, Manassas, VA) from this study. They are, with accession numbers in parenthesis, PFD isolate ALB-IND-25 (MYA-4396), Key lime isolate Hm-1 (MYA-4397), strawberry isolate 02-163 (MYA-4519), blueberry isolate 05-88 (MYA-4520), and three leatherleaf fern isolates: 05-155 (MYA4516), 05-161 (MYA-4517), and 05-200 (MYA-4518).

Pathogenicity assays. Conidial suspensions were prepared from 5- to 7-day-old cultures grown at $23^{\circ} \mathrm{C}$ under constant light on PDA. For inoculations, conidia were washed from dishes, passed through four layers of cheesecloth, and diluted to appropriate concentrations with sterile water. The pathogenicity of isolates on blueberry (Vaccinium corymbosum) and strawberry (Fragaria $\times$ ananassa) was tested using modifications of methods used to screen plants for disease resistance $(5,7,27)$. Blueberry assays were conducted in a greenhouse $\left(10\right.$ to $\left.30^{\circ} \mathrm{C}\right)$ on $\mathrm{cv}$. Gulf Coast during spring 2006, summer 2006, and spring 2007. Clusters of green fruit approximately $5 \mathrm{~mm}$ in diameter were sprayed to runoff with a suspension of $10^{6}$ conidia $/ \mathrm{ml}$ and covered with a clear plastic bag overnight. After the bags were removed, plants remained in a greenhouse. Fruit were harvested when ripe and placed in wells of egg cartons, and the egg cartons were placed in humid chambers at $22^{\circ} \mathrm{C}$. After incubation for 1 week, fruit were scored for ripe-rot symptoms. On inoculation dates, an equal number of fruit clusters were inoculated with each isolate and all isolates were used for the inoculations.

Cv. Camarosa was used for strawberry pathogenicity assays. For detached fruit assays, white-pink fruit were harvested from the field and surface sterilized for $60 \mathrm{~s}$ in $60 \%$ ethanol, rinsed once in sterile water, surface sterilized for $6 \mathrm{~min}$ in a $0.04 \%$ sodium hypochlorite solution, and rinsed twice in sterile water. The fruit were placed in egg carton wells and allowed to dry. A $1.5-\mu$ drop of a suspension of $2 \times 10^{5}$ conidia/ml (300 conidia) was placed on berries when dry and the cartons moved to humid chambers at $22^{\circ} \mathrm{C}$. After 8 days, the fruit were evaluated for lesions and the diameter of lesions measured. Detached fruit assays were conducted on three dates using 21 or 22 fruit/isolate. For disease assays on strawberry foliage, emerging succulent leaves were sprayed to runoff with a $10^{6}$ conidia $/ \mathrm{ml}$ suspension and the inoculated plant placed in a clear plastic bag for $24 \mathrm{~h}$ at $26.5^{\circ} \mathrm{C}$. Upon removal from the bags, plants were kept at $26.5^{\circ} \mathrm{C}$ for an additional 3 days and, subsequently, returned to a greenhouse (at 10 to $30^{\circ} \mathrm{C}$ ) and monitored for 4 weeks. At 4 days postinoculation, the number of lesions per plant was counted and lesion sizes estimated and, at 8 days, the number of girdled petioles per plant was counted. At 4 weeks postinoculation, plants were rated on the scale of Denoyes and Baudry (5), where $0=$ no lesions, $0.5=$ lesion just visible, $1.0=$ single developed lesion; $1.5=$ two

TABLE 1. Description of Colletotrichum acutatum isolates used for pathogenicity and phylogenetic studies

\begin{tabular}{|c|c|c|c|c|c|}
\hline Original host (organ) & Isolate code & Site $^{\mathrm{x}}$ & Pathogenicity & $\begin{array}{c}\text { Sequenced } \\
(G 3 P D, G S, I T S)^{\mathrm{y}}\end{array}$ & $\begin{array}{c}\text { RFLP } \\
(G 3 P D, G S) \\
\end{array}$ \\
\hline Blueberry (fruit) & $05-88$ & Dover, FL, USA & * & $*, *, *$ & $\ldots$ \\
\hline Blueberry (fruit) & $05-148$ & Unknown, NC, USA & * & $*, *, *$ & $\ldots$ \\
\hline Strawberry (petiole) & $02-163$ & Floral City, FL, USA & $*$ & $*, *, *$ & $\ldots$ \\
\hline Strawberry (fruit) & $02-179$ & Plant City, FL, USA & * & $*, *, *$ & $\ldots$ \\
\hline Strawberry (crown) & $03-32$ & Thonotosassa, FL, USA & $*$ & $*, *, *$ & $\ldots$ \\
\hline Sweet orange (flower) & ALB-IND-25z & Indiantown, FL, USA & * & $*, *, *$ & $\ldots$ \\
\hline Key lime (leaf) & $\mathrm{Ss}^{\mathrm{z}}$ & Sarasota, FL, USA & * & $*, *, *$ & $\ldots$ \\
\hline Key lime (leaf) & $\mathrm{Hm}-1^{\mathrm{z}}$ & Homestead, FL, USA & $*$ & $*, *, *$ & $\ldots$ \\
\hline Key lime (leaf) & KLA-Anderson ${ }^{z}$ & Lake Alfred, FL, USA & * & $*, *, *$ & $\ldots$ \\
\hline Leatherleaf fern (frond) & $05-155$ & Pierson, FL, USA (FJ) & * & $*, *, *$ & $\ldots$ \\
\hline Leatherleaf fern (frond) & $05-161$ & Crescent City, FL, USA & $*$ & $*, *, *$ & $\ldots$ \\
\hline Leatherleaf fern (frond) & $05-200$ & Seville, FL, USA & $*$ & $*, *, *$ & $\ldots$ \\
\hline Leatherleaf fern (frond) & $05-121$ & Pierson, FL, USA (FJ) & $\ldots$ & $*, *$ & $\ldots$ \\
\hline Leatherleaf fern (frond) & H8 & Fraijanes, Alajuela, Costa Rica & $\ldots$ & $*, *$ & $\ldots$ \\
\hline Leatherleaf fern (frond) & H12 & Tejar, Cartago, Costa Rica & $\ldots$ & $*, *$ & $\ldots$ \\
\hline Leatherleaf fern (frond) & H19 & Tres Ríos, Cartago, Costa Rica & $\ldots$ & $*, *$ & $\ldots$ \\
\hline Leatherleaf fern (frond) & $\mathrm{H} 24$ & San Pablo, Alajuela, Costa Rica & $\ldots$ & $*, *$ & $\ldots$ \\
\hline Leatherleaf fern (frond) & $\begin{array}{l}\text { 05-116,05-117,05-119, 05-120,05-201,05-202, } \\
05-203,05-205\end{array}$ & Seville FI USA & & & $* *$ \\
\hline Leatherleaf fern (frond) & $05-123,05-124,05-125$ & Pierson, FL, USA (FJ) & $\begin{array}{l}\cdots \\
\cdots\end{array}$ & $\begin{array}{l}\cdots \\
\cdots\end{array}$ & $*, *$ \\
\hline Leatherleaf fern (frond) & $05-131,05-132,05-133$ & Pierson, FL, USA (VP) & $\ldots$ & $\ldots$ & $*, *$ \\
\hline \multirow[t]{2}{*}{ Leatherleaf fern (frond) } & 05-139,05-140,05-142, 05-143, 05-144,05-145, & & & & \\
\hline & $05-146,05-159,05-160,05-162,05-163,05-213$ & Crescent City, FL, USA & $\ldots$ & $\ldots$ & $*, *$ \\
\hline Leatherleaf fern (frond) & $\mathrm{H} 4$ & Cervantes, Cartago, Costa Rica & $\ldots$ & $\ldots$ & $*, *$ \\
\hline Leatherleaf fern (frond) & $\mathrm{H} 7, \mathrm{H} 9$ & Fraijanes, Alajuela, Costa Rica & $\ldots$ & $\ldots$ & $*, *$ \\
\hline Leatherleaf fern (frond) & H13,H15,H16 & Tejar, Cartago, Costa Rica & $\ldots$ & $\ldots$ & $*, *$ \\
\hline
\end{tabular}

${ }^{x}$ City, state or province, and country.

${ }^{y}$ Sequenced regions: $G 3 P D=$ intron 2 of the glyceraldehyde 3-phosphate dehydrogenase gene, $G S=$ intron 2 of the glutamine synthetase gene, and ITS = the internal transcribed spacer (ITS)1, 5.8S rRNA, and ITS2 regions of the rDNA repeat. The G3PD and GS regions were also analyzed for restriction fragment length polymorphisms (RFLP).

${ }^{\mathrm{z}}$ Isolate was previously described in Peres et al. (25). Alternative isolate designations are included in that report. 
lesions; $2.0=$ at least two leaves or petioles with expanded lesions; $2.5=$ stunted plant, but not wilted; $3.0=$ beginning to wilt; $3.5=$ two wilted leaves; $4.0=$ most leaves wilted; $4.5=$ all leaves wilted, but slightly green; and $5.0=$ plant dead. Only the final disease rating was reported for each isolate. Inoculations on strawberry foliage were conducted on four separate dates using one plant per isolate.

For pathogenicity assays on leatherleaf fern (Rumohra adiantiformis) and Key lime (Citrus aurantifolia (Christm.)), a single fern frond at the fiddlehead stage or two immature shoots on a Key lime cutting were sprayed to runoff with a suspension of $10^{6}$ conidia/ml of each isolate on four different dates. Plants were placed in plastic bags at $22^{\circ} \mathrm{C}$ following inoculation and they were returned to a greenhouse $\left(10\right.$ to $\left.30^{\circ} \mathrm{C}\right) 24 \mathrm{~h}$ postinoculation. At 6 days postinoculation for Key lime and 2 weeks postinoculation for leatherleaf fern, the percentage of inoculated tissue that was necrotic was estimated visually.

To evaluate the ability of isolates to produce PFD symptoms, flower clusters on 5- to 10-year-old grafted Orlando tangelo $(C$. reticulata Blanco $\times C$. paradisi Macf.) trees were sprayed to runoff with a suspension of $10^{6} \mathrm{conidia} / \mathrm{ml}$. The flowers were then covered with a plastic bag for $18 \mathrm{~h}$ and the plants held in a greenhouse at 15 to $25^{\circ} \mathrm{C}$. Flower clusters chosen for inoculation contained a large proportion of fully elongated but unopened buds. Flower clusters were inoculated on seven different dates. In total, 12 flower clusters per isolate were inoculated. All 15 isolates were used for inoculations on each date and an equal number of clusters were inoculated with each isolate. The day after inoculation, all buds at any stage of development were counted on each cluster. Five days after inoculations, the total number of open flowers and the number of open flowers with lesions were counted on each cluster. At 60 days postinoculation, persistent calyxes on each flower cluster were counted. For clusters inoculated with the same isolate, the sum of open flowers with necrosis and the sum of the number of open flowers at 5 days postinoculation were used to calculate the percentage of flowers with necrosis. To calculate the percentage of buds giving rise to persistent calyxes, buds counted the day after inoculation were summed and persistent calyxes at 60 days postinoculation were summed for each isolate. For all assays, flowers were sprayed with sterile water as a control. Results of pathogenicity assays for Key lime and PFD isolates on Key lime foliage and Orlando tangelo flowers were reported previously (25).

Statistical analysis of pathogenicity experiments. Percent necrosis on leatherleaf fern fronds and Key lime foliage and disease ratings for strawberry plants inoculated with each isolate or the control were compared using the nonparametric Wilcoxon rank sum test implemented in SAS (version 9.0; SAS Institute, Cary, NC). All pairwise comparisons were made using this statistic and isolates were grouped if the exact two-sided probability, $P>W$, was $>0.05$. Fisher's exact test implemented in SAS was used to compare the percent tangelo flowers with necrosis, the percent flower buds giving rise to persistent calyxes, the percent detached strawberry fruit with anthracnose lesions, and the percent blueberry fruit with ripe rot in assays using flowers or fruit inoculated with each isolate or sprayed with water. Again, all possible pairwise comparisons were made using this test statistic and isolates were grouped if the two-sided table probability was $>0.05$. Logistic analysis in SAS was used to determine if inoculation date and inoculation date-isolate effects on flower necrosis, persistent calyx production, and fruit rots might invalidate conclusions drawn from pooled incidence data. Treatments in which $>95 \%$ or $<5 \%$ of fruit or flowers were diseased on all inoculation dates were excluded from these analyses. Inoculation date and inoculation date-isolate effects were not evident $(P>0.05)$ for any of the dependent variables examined; therefore, their occurrence does not invalidate conclusions from pooled data. PROC MIXED in SAS was used to evaluate lesion diameters on straw- berry fruit caused by isolates from hosts with the ability to infect this fruit. Diameters were square root transformed prior to analysis. Isolate means were compared using least square means $t$ tests and grouped if $P>t$ exceeded 0.05 .

DNA extraction, PCR amplification conditions, and gene sequencing. Mycelia from 2- to 4-day-old cultures grown in $50 \mathrm{ml}$ of Emerson media (4 $\mathrm{g}$ of yeast extract, $15 \mathrm{~g}$ of soluble starch, $1 \mathrm{~g}$ of $\mathrm{K}_{2} \mathrm{HPO}_{4}$, and $0.5 \mathrm{~g}$ of $\mathrm{MgSO}_{4}$ per liter) was collected by vacuum filtration through Whatman no. 3 filter paper and dried overnight in a centrifugal evaporator. DNA was extracted from $60 \mathrm{mg}$ of the dried mycelia using a previously published cetyltrimethylammonium bromide procedure (46) and quantified by comparing the brightness of sample bands to a known quantity of lambda DNA after electrophoresis through a $1 \%$ agarose gel and ethidium bromide staining.

Primers ITS1 (5'-TCCGTAGGTGAACCTGCGG-3') and ITS4 (5'-TCCTCCGCTTATTGATATGC-3') were used to amplify a fragment that includes a 494- to 495-bp region containing ITS1, the gene encoding the 5.8S rRNA subunit, and ITS2 (45). This combined region is described as the ITS region. Primers ITS 1 and ITS4 anneal to genes encoding the small and large subunit rRNA, respectively, and amplify the region spanning bases 1,729 to 2,310 of a reference nuclear rDNA repeat sequence from $\mathrm{Col}$ letotrichum acutatum (GenBank accession no. AJ301936) (23). Primers GDF1 (5'-GCCGTCAACGACCCCTTCATTGA-3') and GDR1 (5'-GGGTGGAGTCGTACTTGAGCATGT-3') were used to amplify a region containing the second intron of the glyceraldehyde-3-phosphate dehydrogenase (G3PD) gene (17). This intron was 209 to $213 \mathrm{bp}$ long depending on the isolate. The primers annealed to coding regions of the $G 3 P D$ gene and amplified a region spanning bases 1,538 to 1,817 of a reference $C$. gloeosporioides isolate (GenBank accession no. M93427) (38). Primers GSF1 (5'-ATGGCCGAGTACATCTGG-3') and GSR1 (5'-GAACCGTCGAAGTTCCAC-3') were used to amplify the second intron of the glutamine synthetase $(G S)$ gene (17). The length of this region was 894 to 910 bp among $C$. acutatum isolates. Both primers annealed to coding regions of the $G S$ and amplified a region spanning bases 326 to 1,340 of a reference $C$. gloeosporioides isolate (GenBank accession no. L78067) (35).

PCR amplifications of the full second intron of the $G S$ were inconsistent from template DNA of leatherleaf fern isolates using the GSF1/GSR1 primer set. For this reason, three additional primer pairs were designed to amplify subregions of the second intron of the $G S$ from leatherleaf fern isolates for additional sequencing and for RFLP analysis. Primer pairs FernGS1 (5'GGTACGTTCACACAACAACCACC-3')/FernGS3 (5'-CGTGGAGAACAGTAACGACC-3') and FernGS4 (5'-TGGAGGTCTTGCGAGTTGCT-3')/FernGS5 (5'-CTCCTTGAGAGTCTATGGAGGC-3') were used to produce sequencing templates. Primers FernGS1 and FernGS5 overlap the exon/intron and intron/exon junction, respectively. Primers FernGS3 and FernGS4 annealed to regions within the second intron of $C$. acutatum isolates from leatherleaf fern. FernGS1/FernGS3 produced a 702- to 712-bp product and FernGS4/FernGS5 produced a 324- to 332-bp product. A third primer pair, FernGS1 (5'-GGTACGTTCACACAACAACCACC-3')/FernGS2 (5'-CGCTATTCCCAGCCGGAAGT-3') was used to amplify 289 to 292 bp of the $5^{\prime}$ end of the $G S$ second intron from leatherleaf fern isolates for RFLP analysis described below. The primers designed from fern sequence data successfully amplified a product from template DNA of all leatherleaf fern isolates.

PCR reactions to prepare template for sequencing were carried out in a $120-\mu \mathrm{l}$ volume with $20 \mathrm{ng}$ of genomic DNA template and, to prepare product for RFLP analysis, reactions were carried out in a $25-\mu$ l volume with $4 \mathrm{ng}$ of genomic DNA template. For the ITS1/ITS4 and GDF1/GDR1 primer sets, reactions contained 1× reaction buffer $(10 \mathrm{mM}$ Tris [pH 9], $50 \mathrm{mM} \mathrm{KCl}$, and $2 \mathrm{mM}$ $\mathrm{MgCl}_{2}$ ) with $200 \mu \mathrm{M} \mathrm{dNTP,} 500 \mathrm{nM}$ concentration of both 
primers, and Taq DNA polymerase at $0.04 \mathrm{U} / \mu \mathrm{l}$. Cycling parameters consisted of a 4-min denaturing step at $94^{\circ} \mathrm{C}$; followed by 34 cycles at $94^{\circ} \mathrm{C}$ for $45 \mathrm{~s}, 52^{\circ} \mathrm{C}$ (ITS1/ITS4) or $60^{\circ} \mathrm{C}$ (GDF1/ GDR1) for $45 \mathrm{~s}$, and $72^{\circ} \mathrm{C}$ for $1 \mathrm{~min}$; and a single step at $72^{\circ} \mathrm{C}$ for $5 \mathrm{~min}$. For the GSF1/GSR1 primer set, the reactions contained $1 \times$ reaction buffer $(10 \mathrm{mM}$ Tris $[\mathrm{pH} 8.3], 50 \mathrm{mM} \mathrm{KCl}, 1.5 \mathrm{mM}$ $\mathrm{MgCl}_{2}$, and $0.001 \%$ gelatin) with $200 \mu \mathrm{M} \mathrm{dNTP}, 400 \mathrm{nM}$ concentration of both primers, and Taq DNA polymerase at $0.04 \mathrm{U} / \mu \mathrm{l}$ added during the denaturing step. The cycling parameters for GSF1/GSR1 consisted of a 4-min denaturing step at $94^{\circ} \mathrm{C}$; followed by 35 cycles at $94^{\circ} \mathrm{C}$ for $1 \mathrm{~min}, 55^{\circ} \mathrm{C}$ for $1 \mathrm{~min}$, and $72^{\circ} \mathrm{C}$ for $1.5 \mathrm{~min}$; and a single step at $72^{\circ} \mathrm{C}$ for $5 \mathrm{~min}$. For the primer pairs FernGS1/FernGS2, FernGS1/FernGS3, and FernGS4/ FernGS5, reactions contained $1 \times$ reaction buffer $(10 \mathrm{mM}$ Tris[pH 9], $50 \mathrm{mM} \mathrm{KCl}$, and $2 \mathrm{mM} \mathrm{MgCl}_{2}$ ) with $200 \mu \mathrm{M}$ dNTP, $400 \mathrm{nM}$ concentration of both primers, and Taq DNA polymerase at 0.04 $\mathrm{U} / \mu \mathrm{l}$. Cycling parameters consisted of a 4-min denaturing step at $94^{\circ} \mathrm{C}$; followed by 34 cycles at $94^{\circ} \mathrm{C}$ for $45 \mathrm{~s}, 60^{\circ} \mathrm{C}$ for $45 \mathrm{~s}$, and $72^{\circ} \mathrm{C}$ for $1 \mathrm{~min}$; and a single step at $72^{\circ} \mathrm{C}$ for $5 \mathrm{~min}$. PCR product used for sequencing was concentrated to $20 \mathrm{ng} / \mu \mathrm{l}$ with a Microcon YM-30 centrifugal filter (Millipore, Billerica, MA) and $15-\mu l$ samples were submitted to the University of Florida Interdisciplinary Center for Biotechnology Research in Gainesville for sequencing. Sequence data were generated in forward and reverse directions from fluorescent cycle sequencing reactions using an automated sequencer (Perkin-Elmer/Applied Biosystems, Foster City, CA). All of the reported PCR primers were also used as sequencing primers, with the exception of primers FernGS2, FernGS3, and FernGS4. Two additional sequencing primers, SeqFernGS1 (5'-AGCAACTCGCAAGACCTCCA-3') and SeqFernGS2 (5'-GGCGCGTCTTCGGTGAA-3'), were used to obtain sequence data from FernGS1/FernGS3 and FernGS4/ FernGS5 PCR products, respectively. These additional primers were used to alleviate sequence ambiguities caused by the occurrence of a cytosine repeat within the $G S$ of leatherleaf fern isolates. Accession numbers of sequences reported to GenBank (National Center for Biotechnological Information, Bethesda, MD) are presented in Table 2.

Gene trees. Only sequence data from the C. acutatum isolates evaluated for pathogenicity were used for construction of gene trees. Sequence alignments were done using CLUSTAL W (41). C. gloeosporioides is a closely related species to C. acutatum and $I T S, G 3 P D$, and $G S$ sequences were available from GenBank for C. gloeosporioides isolate NC329 (G3PD accession no.

TABLE 2. Accession numbers for sequences from Colletotrichum acutatum isolates deposited into GenBank ${ }^{y}$

\begin{tabular}{lccc}
\hline & \multicolumn{3}{c}{ Locus $^{\mathrm{z}}$} \\
\cline { 2 - 4 } Isolate code & ITS & G3PD & $G S$ \\
\hline $05-88$ & EU647299 & EU647312 & EU647325 \\
$05-148$ & EU647300 & EU647313 & EU647326 \\
$05-197$ & EU647301 & EU647314 & EU647327 \\
$02-163$ & EU647302 & EU647315 & EU647328 \\
$02-179$ & EU647303 & EU647316 & EU647329 \\
$03-32$ & EU647304 & EU647317 & EU647330 \\
ALB-IND-25 & EU168901 & EU168905 & EU647331 \\
OCO-ARC-4 & EU647305 & EU647318 & EU647332 \\
STF-FTP-10 & EU647306 & EU647319 & EU647333 \\
Ss & EU647307 & EU647320 & EU647334 \\
Hm-1 & EU168903 & EU168907 & EU647335 \\
KLA-Anderson & EU647308 & EU647321 & EU647336 \\
$05-155$ & EU647309 & EU647322 & EU647337 \\
$05-161$ & EU647310 & EU647323 & EU647338 \\
$05-200$ & EU647311 & EU647324 & EU647339 \\
\hline
\end{tabular}

${ }^{y}$ Sequences for an isolate were deposited into GenBank if all three loci were sequenced and the pathogenicity profile of the isolate was determined.

${ }^{\mathrm{z}} I T S=$ the ITS1, 5.8S rRNA, and ITS2 regions of the rDNA repeat; $G 3 P D=$ intron 2 of the glyceraldehyde 3-phosphate dehydrogenase gene; and $G S=$ intron 2 of the glutamine synthetase gene.
DQ792849, GS accession no. DQ792872, and ITS accession no. DQ003087) $(9,22)$. In a preliminary analysis, the potential of using this isolate as an outgroup to root trees constructed with $C$. acutatum isolates was evaluated. Inclusion of NC329 substantially elevated homoplasy and retention index (RI) values and may have interfered with proper alignment of $G 3 P D$ and $G S$ sequences from $C$. acutatum isolates. For these reasons, the isolate was excluded from final trees and the trees were midpoint rooted. However, a comparison of the position of the midpoint root to the outgroup root was reported. A heuristic search implemented in PAUP 4.0 (Sinauer Associates, Inc., Sunderland, MA) was used to find maximum parsimony (MP) trees. The search employed 1,000 random stepwise addition replicates and the treebisection-reconstruction branch-swapping algorithm. Gaps were not used for tree construction, and transitions and transversions were weighted equally. Support for nodes of parsimony trees were obtained from 1,000 bootstrapped data sets. Maximum likelihood (ML) trees for ITS, G3PD, and $G S$ sequence data were determined from a heuristic search employing the tree bisection-reconnection algorithm in PAUP 4.0. Bayesian posterior probabilities of ML tree nodes were determined with MrBayes 3.1.2 (29). Four chains were run for each analysis using MrBayes, one cold and three heated. The temperature parameter was set to 0.2. In all, 600,000 generations were run and trees sampled every 400 generations. The burn-in period consisted of the first 200,000 generations. Sequence evolution models were determined using FINDMODEL (Los Alamos National Laboratory, Los Alamos, $\mathrm{NM}$ ), a web implementation of MODELTEST (28). For ITS sequences, the F81 model (10) was used; for G3PD sequences, the K80 model (20); and for $G S$ sequences, an HKY + gamma model (18). ML trees had the same topology as MP trees and are not reported. Bayesian posterior probability estimates are reported at nodes on MP trees. A partitioned matrix that includes aligned ITS, $G 3 P D$, and $G S$ sequences for isolates used to construct trees and the actual trees depicted in Figure 1 were deposited in TreeBASE (matrix accession no. M4118 and study accession no. S2171).

Group designation. Isolates were assigned to $C$. acutatum groups by comparing generated sequences with sequences reported in public data bases for isolates already assigned a group designation. Primarily ITS sequences were available for comparison. Guerber et al. (17) included isolates from all five hosts in their study that identified genetic groups within $C$. acutatum from $G S$ and $G 3 P D$ sequence data, but these sequences were not deposited in a database. ITS sequences from some isolates in that study were available and used for comparisons. The G3PD and ITS sequences of Key lime and PFD isolates were previously compared with isolates included in the Guerber et al. (25) study. Colony color and conidia shape was also used to assign isolates to genetic groups.

Test for recombination among isolates. The partition homogeneity test (PHT), used before to detect recombination in Aspergillus flavus (15), was applied to test the null hypothesis that there was no evidence for recombination among $C$. acutatum isolates used to construct gene trees. The PHT creates artificial data sets in which polymorphic nucleotides are swapped randomly between loci of individuals. Subsequently, MP trees are made from the artificial data sets and the tree lengths at each locus summed. In the absence of any recombination, gene trees from different loci should be perfectly concordant and swapping nucleotides should not increase the sum of the tree lengths. Recombination events among loci would tend to introduce homoplasy into the data set. The increase in homoplasy is then detected by an increase in the sum of tree lengths in the artificial data set when compared with the original. The PHT was conducted in PAUP 4.0. The probability of obtaining the summed branch length observed for original trees in swapped data sets was based on 1,000 repetitions. Parsimony trees were determined using the same search algorithm as described earlier for ITS, G3PD, and GS 
sequences. The PHT test, under certain conditions, has a higher than expected type I error $(2,8)$. These conditions include excess homoplasy in at least one or more data sets, unequal branch lengths, and rate variance among data sets (2). At noise levels observed within trees used for this test (RI > 0.98), the type I error rate should not have exceeded expected values using all of the sequence data from Florida isolates (2). However, analyses were also conducted without the blueberry isolates and ITS sequence data. The blueberry isolates were excluded to reduce branch-length variation and to determine the effect of excluding group $\mathrm{C}$ isolates, which produce a teleomorph, on the results of the PHT. The ITS region was excluded because the mutation rate of this sequence was lower than that of the others.

Comparison of leatherleaf fern isolates from the United States and Costa Rica. Among leatherleaf fern isolates from the United States used in pathogenicity assays, there were two distinct $G 3 P D$ and $G S$ sequences. To further evaluate the genetic diversity at these two loci within the leatherleaf fern population, the $G 3 P D$ and $G S$ region was sequenced from an additional isolate obtained at each of the three sites in the United States where the isolates used for pathogenicity assays were obtained, two isolates from a second fernery in Pierson, FL, and five isolates from different ferneries in two provinces of Costa Rica. MP and ML trees were then constructed using sequence from the $G 3 P D$ and $G S$ regions of these isolates and isolates previously evaluated. The tree construction methodology was the same as that reported above. One to twelve additional leatherleaf fern isolates from each of the nine sites in the United States and Costa Rica were evaluated by RFLP analysis. Restriction digestion of the GDF1/GDR1 PCR product with the enzyme RcaI yielded either a 273-bp uncut product or bands 208 and 65 bp in length. Restriction digestion of the FernGS1/FernGS2 PCR product with $B s t$ UI yielded either a 292-bp uncut product or bands 149 and 140 bp in length. Restriction digests were done according to the manufacturer's instructions and bands separated through a $2 \%$ agarose gel.

\section{RESULTS}

Cross-pathogenicity of isolates. The incidence of anthracnose lesions on strawberry fruit was highest for fruit inoculated with strawberry isolates (Table 3). Fruit inoculated with all three blueberry isolates had a higher incidence of anthracnose than control fruit, although only one of the three blueberry isolates (05-148) had an incidence similar to any strawberry isolate. In addition to the higher incidence, lesions on fruit infected with strawberry isolates were larger than those on fruit infected with blueberry isolates (Table 3). The low level of disease in the control $(1.6 \%)$ resulted from natural infections in the field where strawberry fruit were harvested. Strawberry fruit inoculated with only one isolate, PFD isolate ALB-IND-25, from a host other than blueberry or strawberry had an anthracnose incidence higher than the control. Given that none of the other PFD isolates had more disease than the control, the relatively low disease incidence for fruit inoculated with ALB-IND-25, and the numerous pairwise comparisons with the control that were conducted, the statistically higher disease incidence for this isolate may have resulted from chance. Blueberry ripe-rot incidence was higher than the control only for fruit inoculated with isolates from blueberry (Table 3). For inoculations on strawberry, leatherleaf fern, and Key lime foliage,

\section{A rRNA (5.8S rRNA, ITS1, ITS2)}

\section{B Glyceraldehyde 3-phosphate dehydrogenase $2^{\text {nd }}$ Intron}

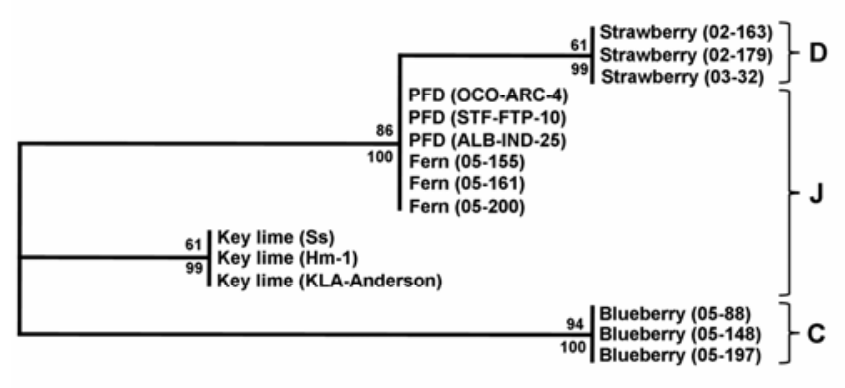

1 substitution

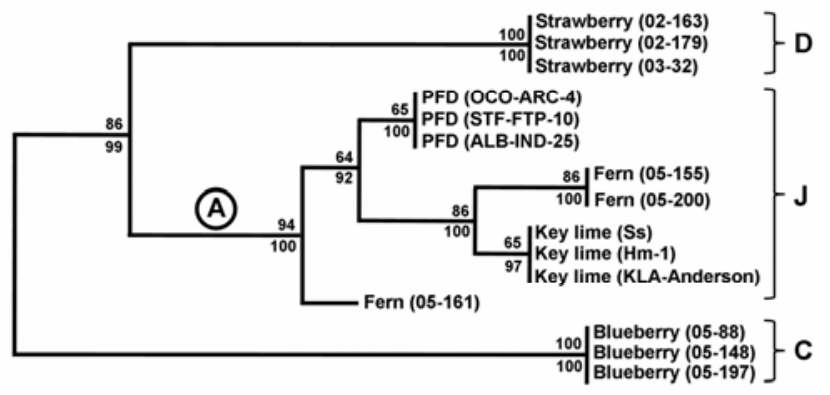

1 substitution

\section{Glutamine synthetase $2^{\text {nd }}$ Intron}

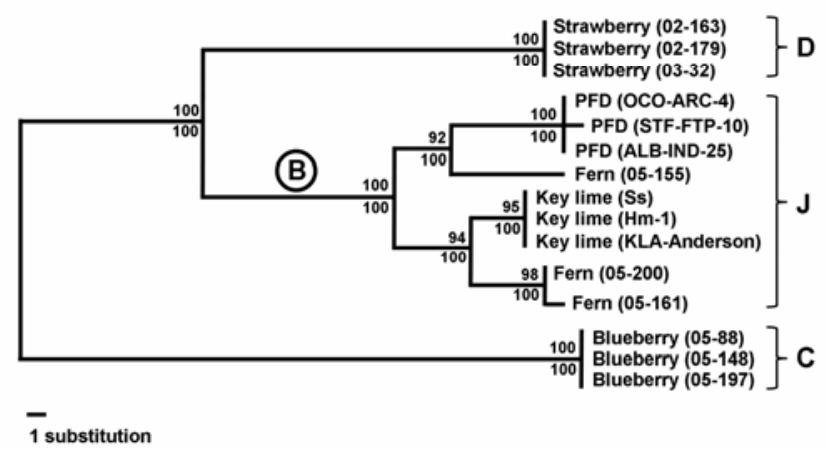

Fig. 1. Maximum parsimony (MP) trees based on sequence from the A, internal transcribed spacer (ITS) 1, 5.8S, and ITS2 regions of the ribosomal DNA; B, the second intron of the glyceraldehyde-3-phosphate dehydrogenase gene $(G 3 P D)$; and $\mathbf{C}$, the second intron of the glutamine synthetase $(G S)$ gene. The numbers above nodes are the bootstrap values determined for MP trees (shown) and numbers below nodes are Bayesian posterior probabilities for maximum likelihood trees that had the same topologies as MP trees (not shown). Letters D, J, and C to the right of trees show group designations for isolates to the left. The circled letters A and B identify branches leading into clades depicted in Figure 2. 
only plants inoculated with isolates from the homologous host had disease ratings or percentages of necrotic tissue higher than levels observed for the controls (Table 4). The percentage of open tangelo flowers inoculated with PFD, Key lime, blueberry, and strawberry isolates that were necrotic at 5 days postinoculation was higher than for control flowers (Table 5). The percentage of necrotic flowers in clusters inoculated with leatherleaf fern isolates was no greater than in control clusters. Among the isolates that produced necrosis on flowers, PFD isolates had the highest percentage of flowers necrotic ( 90.2 to $100 \%)$. Among isolates from blueberry, strawberry, and Key lime, there was no trend suggesting that isolates from any particular host were more or less pathogenic than isolates from the others. Based on percentages of buds that gave rise to persistent calyxes, isolates were not easily separated (Table 5). Persistent calyx formation tended to be greatest for buds inoculated with PFD isolates but the highest percentage of flower buds that gave rise to persistent calyxes was for a Key lime isolate. Isolates from the other hosts that caused symptoms on flower petals (Key lime, blueberry, and strawberry) also produced persistent calyxes at percentages comparable with PFD isolates.

Analysis of gene trees. There was one MP tree constructed from the ITS, G3PD, and $G S$ regions of the isolates used for pathogenicity studies (Fig. 1). Within the ITS region, there were seven parsimony informative sites and no uninformative sites. The MP tree constructed from sequences in this region required seven nucleotide transitions, the homoplasy index (HI) was 0.0, and the RI was 1.0. There were 27 parsimony informative sites and one uninformative site within the G3PD intron. The MP tree for this region required 30 transitions, the $\mathrm{HI}=0.033$, and the $\mathrm{RI}=0.99$. Within the $G S$ intron, there were 85 parsimony informative and four uninformative sites. The MP tree for this region required 95 transitions, the $\mathrm{HI}=0.042$, and the RI $=0.98$. ML trees constructed for each region had the same topology as MP trees (not shown). Overall statistical support for the occurrence of clades observed using both tree construction methods was strong, as demonstrated by high bootstrap values and Bayesian posterior probabilities. However, support for clades was reduced in the tree constructed from ITS sequence data and in the portion of the tree constructed from $G 3 P D$ sequence data containing PFD, leather- leaf fern, and Key lime isolates. This was likely due to the lower substitution rate of the ITS region and the relatively close relationship between the PFD, leatherleaf fern, and Key lime isolates. In the trees constructed from ITS, G3PD, and $G S$ sequences, isolates from strawberry, Key lime, and blueberry grouped into three different clades, with isolates from the same host composing each clade (Fig. 1A to $\mathrm{C}$ ). There was no sequence variation within these clades. Based on ITS sequence data, PFD and leatherleaf fern isolates grouped together (Fig. 1A), although there was an insertion or deletion that was not used for phylogenetic analysis that distinguished the isolates. PFD isolates formed a distinct clade in trees constructed from the G3PD and $G S$ intron regions (Fig. 1B and C). There was a single nucleotide difference in the $G S$ region between isolates from PFD-affected citrus (Fig. 1C). Leatherleaf fern isolates did not occur in the same clade in trees constructed from the G3PD and $G S$ sequences (Fig. $1 \mathrm{~B}$ and C). Based on G3PD sequence data, isolates 05-155 and 05-200 grouped together and, based on the $G S$ sequence data, isolates $05-$ 161 and 05-200 grouped together. Six substitutions in the G3PD differentiated isolate 05-161 from isolates 05-155 and 05-200, and 13 to 14 substitutions and four insertion or deletion events in the $G S$ region differentiated isolate $05-155$ from isolates $05-161$ and $05-200$.

Inclusion of $C$. gloeosporioides isolate NC329 as an outgroup rooted $G 3 P D$ and $G S$ trees on the branch separating blueberry isolates from all other isolates, producing $C$. acutatum isolate clades identical to those of the reported midpoint-rooted trees for these genes (Fig. 1B and C). For the ITS tree, inclusion of $C$. gloeosporioides isolate NC329 rooted the tree on the branch separating Key lime and blueberry isolates from PFD, leatherleaf fern, and strawberry isolates. This differed from the reported ITS tree which did not group Key lime and blueberry isolates into a clade (Fig. 1A).

Group designations. The blueberry isolates were all group $\mathrm{C}$ isolates; those from strawberry were group D isolates; and the PFD, Key lime, and Leatherleaf fern isolates were group $\mathbf{J}$ isolates (Fig. 1A to C). The ITS region from blueberry isolates was identical to the ITS region of isolates from multiple hosts reported in GenBank. Among the isolates were two well-characterized isolates, PCN5 (GenBank accession no. AF272786) from pecan and

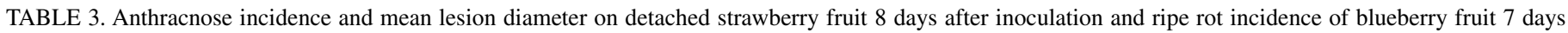
after harvest $^{\mathrm{w}}$

\begin{tabular}{|c|c|c|c|c|c|}
\hline \multirow[b]{2}{*}{ Host or disease $(\text { code })^{x}$} & \multicolumn{3}{|c|}{ Strawberry } & \multicolumn{2}{|c|}{ Blueberry } \\
\hline & Fruit inoculated (n) & Decayed fruit $(\%)^{\mathrm{y}}$ & Lesion diameter $(\mathrm{mm})^{\mathrm{z}}$ & Fruit inoculated (no.) & Decayed fruit $(\%)^{\mathrm{y}}$ \\
\hline Strawberry (02-163) & 64 & $64.1 \mathrm{a}$ & $12.1 \mathrm{a}$ & 62 & $3.2 \mathrm{c}$ \\
\hline Strawberry (03-32) & 63 & $50.8 \mathrm{a}$ & $11.6 \mathrm{a}$ & 57 & $8.8 \mathrm{c}$ \\
\hline Strawberry (02-179) & 65 & $49.2 \mathrm{ab}$ & $10.6 \mathrm{ab}$ & 67 & $7.4 \mathrm{c}$ \\
\hline Blueberry (05-148) & 59 & $32.2 \mathrm{bc}$ & $6.3 \mathrm{c}$ & 69 & $39.1 \mathrm{~b}$ \\
\hline Blueberry (05-197) & 62 & $25.8 \mathrm{~cd}$ & $6.9 \mathrm{c}$ & 75 & $42.7 \mathrm{~b}$ \\
\hline Blueberry $(05-88)$ & 62 & 19.4 cde & $7.9 \mathrm{bc}$ & 64 & $62.5 \mathrm{a}$ \\
\hline PFD (ALB-IND-25) & 61 & $14.8 \mathrm{def}$ & $\ldots$ & 62 & $3.2 \mathrm{c}$ \\
\hline Key lime (Ss) & 63 & $11.1 \mathrm{efg}$ & $\ldots$ & 80 & $1.3 \mathrm{c}$ \\
\hline Key lime (KLA-Anderson) & 61 & $6.6 \mathrm{efg}$ & $\ldots$ & 59 & $3.4 \mathrm{c}$ \\
\hline PFD (STF-FTP-10) & 63 & $6.4 \mathrm{fg}$ & $\ldots$ & 55 & $1.8 \mathrm{c}$ \\
\hline Fern $(05-200)$ & 64 & $6.3 \mathrm{fg}$ & $\ldots$ & 70 & $2.9 \mathrm{c}$ \\
\hline PFD (OCO-ARC-4) & 63 & $4.8 \mathrm{fg}$ & $\ldots$ & 51 & $2.0 \mathrm{c}$ \\
\hline Fern (05-155) & 62 & $3.2 \mathrm{~g}$ & $\ldots$ & 57 & $7.0 \mathrm{c}$ \\
\hline Fern $(05-161)$ & 62 & $3.2 \mathrm{~g}$ & $\ldots$ & 73 & $1.4 \mathrm{c}$ \\
\hline Control & 61 & $1.6 \mathrm{~g}$ & $\ldots$ & 102 & $2.0 \mathrm{c}$ \\
\hline Key lime (Hm-1) & 63 & $1.6 \mathrm{~g}$ & $\ldots$ & 52 & $1.9 \mathrm{c}$ \\
\hline
\end{tabular}

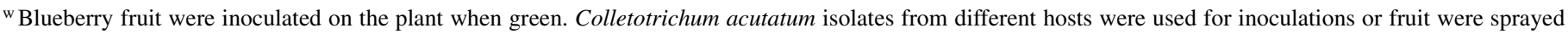
with water as a control.

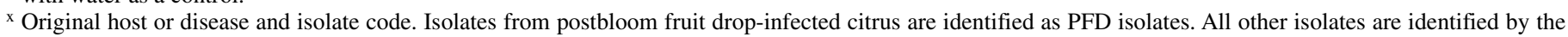
common name of their host.

y $P$ value obtained from Fisher's exact test comparing means followed by the same letter exceeded 0.05 .

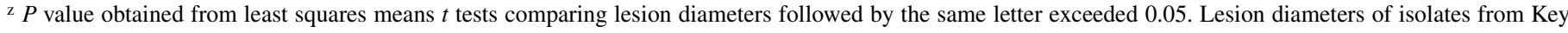
lime, fern, and PFD-affected citrus were not compared due to the low incidence of fruit with lesions. Reported means for lesion diameter were calculated by backtransforming means for the square root of lesion diameter. 
isolate ATCC MYA-662 (GenBank accession no. DQ286121) from apple. The pink-pigmented isolate PCN5 was described as a subgroup I isolate by Freeman et al. (12), a group that corresponds to group C of Guerber et al. (17,33). Isolate ATCC MYA662 was also characterized as a group $C$ isolate (17). Group $C$ is composed primarily of fruit-rot isolates from hosts such as apple, peach, blueberry, almond, pecan, and strawberry $(12,17)$. Isolates from this group are typically pink in culture and have fusiform conidia $(3,12)$. The blueberry isolates obtained in the present study were chromogenic pink in culture and had fusiform conidia, similar to blueberry isolates from other regions of the United States $(6,32)$. There was no evidence that the blueberry isolates belonged to a new group, designated group A9, which is composed of isolates from blueberry as well as a number of other hosts in Australia (44). The ITS region of strawberry isolates also matched that of isolates from multiple hosts in GenBank. Among the isolates was the strawberry isolate TUT-5954 (GenBank accession no. AF207794), described by Denoyes-Rothan et al. (6) as a CA-clonal group isolate and strawberry isolate S2 (39) (GenBank accession no. DQ454018) that groups with the recently described epitype for $C$. acutatum (40). Isolate TUT-5954 possessed an arbitrarily primed PCR DNA banding pattern identical to a strawberry isolate, TUT-7E, described as a group D isolate $(11,17)$. The Florida strawberry isolates produced fusiform conidia and were orange in culture. Isolates from the globally distributed CA-clonal group have these same morphological traits (6). Sequences of the ITS and G3PD regions for the three PFD and three Key lime isolates were previously compared with a population of PFD and Key lime isolates that included isolates from Guerber et al. (17) and were found to be group J isolates (25). The ITS region of Florida leatherleaf fern isolates was the same as that of leatherleaf fern isolates from Costa Rica (30). Sequences for fern isolates from the United States were not present in any public database; however, leatherleaf fern isolates were included in published trees constructed from $G S$ and $G 3 P D$ sequences (17). In trees constructed from both regions, leatherleaf fern isolates fell into the group J clade along with PFD and Key lime isolates, and the distance between Key lime isolates and leatherleaf fern isolates was less than that between Key lime and PFD isolates. Most of the leatherleaf fern isolates occupied this same position (Fig. 1B and $\mathrm{C}$ ). Also, isolates from group $\mathrm{J}$ generally do not produce

TABLE 4. Strawberry anthracnose disease ratings and the percentage of immature leatherleaf fern and Key lime foliage that was necrotic after inoculation with Colletotrichum acutatum isolates from different hosts or sprayed with water as a control ${ }^{\mathrm{y}}$

\begin{tabular}{|c|c|c|c|}
\hline \multirow[b]{2}{*}{ Host or disease $(\text { code })^{\mathrm{z}}$} & \multirow{2}{*}{$\frac{\text { Disease rating }(0-5)}{\text { Strawberry }}$} & \multicolumn{2}{|c|}{ Necrosis $(\%)$} \\
\hline & & Fern & Key lime \\
\hline Strawberry (02-179) & $3.8 \mathrm{a}$ & $0.0 \mathrm{c}$ & $0.0 \mathrm{~b}$ \\
\hline Strawberry (03-32) & $3.5 \mathrm{a}$ & $0.0 \mathrm{c}$ & $0.0 \mathrm{~b}$ \\
\hline Strawberry (02-163) & $2.9 \mathrm{a}$ & $0.5 \mathrm{c}$ & $0.1 \mathrm{~b}$ \\
\hline Key lime (Hm-1) & $0.4 \mathrm{~b}$ & $0.0 \mathrm{c}$ & $60.6 \mathrm{a}$ \\
\hline Fern $(05-161)$ & $0.1 \mathrm{~b}$ & $78.8 \mathrm{a}$ & $0.0 \mathrm{~b}$ \\
\hline Fern $(05-155)$ & $0.1 \mathrm{~b}$ & $17.5 \mathrm{~b}$ & $0.0 \mathrm{~b}$ \\
\hline Key lime (Ss) & $0.1 \mathrm{~b}$ & $0.0 \mathrm{c}$ & $31.8 \mathrm{a}$ \\
\hline Fern $(05-200)$ & $0.0 \mathrm{~b}$ & $61.3 \mathrm{ab}$ & $0.0 \mathrm{~b}$ \\
\hline Blueberry (05-197) & $0.0 \mathrm{~b}$ & $0.3 \mathrm{c}$ & $0.0 \mathrm{~b}$ \\
\hline Key lime (KLA-Anderson) & $0.0 \mathrm{~b}$ & $0.0 \mathrm{c}$ & 29.9 a \\
\hline PFD (STF-FTP-10) & $0.0 \mathrm{~b}$ & $0.0 \mathrm{c}$ & $0.1 \mathrm{~b}$ \\
\hline PFD (ALB-IND-25) & $0.0 \mathrm{~b}$ & $0.0 \mathrm{c}$ & $0.0 \mathrm{~b}$ \\
\hline Blueberry (05-88) & $0.0 \mathrm{~b}$ & $0.0 \mathrm{c}$ & $0.0 \mathrm{~b}$ \\
\hline Blueberry (05-148) & $0.0 \mathrm{~b}$ & $0.0 \mathrm{c}$ & $0.0 \mathrm{~b}$ \\
\hline PFD (OCO-ARC-4) & $0.0 \mathrm{~b}$ & $0.0 \mathrm{c}$ & $0.0 \mathrm{~b}$ \\
\hline Control & $0.0 \mathrm{~b}$ & $0.0 \mathrm{c}$ & $0.0 \mathrm{~b}$ \\
\hline
\end{tabular}

y $P$ value obtained from the Wilcoxon rank sum test comparing disease ratings among isolates with means followed by the same letter exceeded 0.05 .

${ }^{\mathrm{z}}$ Original host or disease and isolate code. Isolates from postbloom fruit dropinfected citrus are identified as PFD isolates. All other isolates are identified by the common name of their host. fusiform conidia $(4,23)$ and this was true for the PFD, Key lime, and leatherleaf fern isolates.

Evidence for recombination. The topology of trees in the area that included the strawberry, PFD, leatherleaf fern, and Key lime isolates was not consistent. For example, strawberry isolates occupied a different position relative to PFD, leatherleaf fern, and Key lime in the tree constructed from ITS data and the position of leatherleaf fern isolates 05-161 and 05-200 was not consistent in the trees constructed from $G 3 P D$ and $G S$ introns. These discrepancies in tree topologies suggested a history of recombination among the sampled isolates. Assuming a complete absence of any historical recombination, an MP tree constructed from sequences of each region combined should have the same number of steps as the sum of steps for trees constructed from regions individually because recombination would not introduce additional homoplasy. The number of steps required to construct a tree when all sequences were combined was nine steps greater than the sum of individual tree lengths for the three loci (Table 6). When ITS

TABLE 5. Postbloom fruit drop symptoms on Orlando tangelo flower clusters inoculated with Colletotrichum acutatum isolates from different hosts or sprayed with water

\begin{tabular}{|c|c|c|c|}
\hline Host or disease $(\operatorname{code})^{\mathrm{x}}$ & $\begin{array}{l}\text { Open flowers, } \\
\text { total buds }\end{array}$ & $\begin{array}{c}\text { Necrotic } \\
\text { flowers }(\%)^{\mathrm{z}}\end{array}$ & $\begin{array}{c}\text { Persistent } \\
\text { calyxes }(\%)^{z}\end{array}$ \\
\hline PFD (ALB-IND-25) & 80,155 & $100.0 \mathrm{a}$ & 6.5 bcde \\
\hline PFD (OCO-ARC-4) & 93,158 & $97.9 \mathrm{a}$ & $13.3 \mathrm{ab}$ \\
\hline PFD (STF-FTP-10) & 92,199 & $90.2 \mathrm{~b}$ & $11.6 \mathrm{ab}$ \\
\hline Key lime (Hm-1) & 86,187 & $46.5 \mathrm{c}$ & $17.6 \mathrm{a}$ \\
\hline Blueberry (05-197) & 73,177 & $45.2 \mathrm{~cd}$ & $6.8 \mathrm{bcd}$ \\
\hline Blueberry (05-88) & 67,178 & 41.8 cde & $12.9 \mathrm{ab}$ \\
\hline Blueberry (05-148) & 73,159 & 38.4 cde & $7.6 \mathrm{bc}$ \\
\hline Strawberry (03-32) & 59,124 & 37.3 cde & $4.8 \mathrm{cdef}$ \\
\hline Key lime (Ss) & 76,157 & 34.2 cde & 2.5 cdef \\
\hline Strawberry (02-163) & 90,210 & 33.3 cde & $1.0 \mathrm{fg}$ \\
\hline Key lime (KLA-Anderson) & 92,189 & $30.4 \mathrm{de}$ & 5.3 cde \\
\hline Strawberry (02-179) & 71,172 & $26.8 \mathrm{e}$ & $2.9 \mathrm{cdef}$ \\
\hline Fern $(05-155)$ & 55,147 & $10.9 \mathrm{f}$ & 2.0 defg \\
\hline Fern $(05-200)$ & 86,234 & $4.7 \mathrm{f}$ & $2.6 \mathrm{def}$ \\
\hline Fern $(05-161)$ & 70,129 & $4.3 \mathrm{f}$ & $1.6 \mathrm{efg}$ \\
\hline Water control & 99,214 & $3.0 \mathrm{f}$ & $0.0 \mathrm{~g}$ \\
\hline
\end{tabular}

${ }^{x}$ Original host or disease and isolate code. Isolates from postbloom fruit dropinfected citrus are identified as PFD isolates. All other isolates are identified by the common name of their host.

y Total number of open flowers evaluated to determine the percentage of flowers with necrosis and the total number of buds inoculated used to determine the percentage of buds that became persistent calyxes.

${ }^{\mathrm{z}} P$ value obtained from Fisher's exact test comparing means followed by the same letter exceeded 0.05 .

TABLE 6. Actual and minimum possible maximum parsimony tree lengths for trees constructed from sequences at three loci separately and combined

\begin{tabular}{lccc}
\hline Excluded isolates, locus ${ }^{\mathrm{y}}$ & Tree length & $\begin{array}{c}\text { Minimum } \\
\text { tree length }\end{array}$ & Excess steps \\
\hline None & 7 & 7 & 0 \\
$\quad I T S$ & 30 & 29 & 1 \\
G3PD & 95 & 91 & 4 \\
GS & 141 & $132^{\mathrm{z}}$ & 9 \\
ITS, G3PD, GS combined & 132 & $125^{\mathrm{z}}$ & 7 \\
G3PD, GS combined & & & \\
Blueberry & 4 & 4 & 0 \\
ITS & 18 & 18 & 3 \\
$G 3 P D$ & 56 & 53 & 7 \\
$G S$ & 85 & $78^{\mathrm{z}}$ & 7 \\
ITS, G3PD, GS combined & 81 & $74^{\mathrm{z}}$ & 0 \\
G3PD, GS combined & & & \\
\hline
\end{tabular}

${ }^{\mathrm{y}}$ Host of the isolates shown in Figure 1. ITS = the ITS1, 5.8S rRNA, and ITS2 regions of the rDNA repeat; $G 3 P D=$ intron 2 of the glyceraldehyde 3-phosphate dehydrogenase gene; and $G S=$ intron 2 of the glutamine synthetase gene.

${ }^{\mathrm{z}}$ The minimum possible length for the tree constructed from loci combined was the sum of the actual tree lengths for trees constructed using sequence from each locus individually. 
sequences or the blueberry isolates were excluded from the analysis, the number of steps required to construct a tree when all sequences were combined was seven greater than the sum of individual tree lengths. These results suggest that combining sequences introduced additional homoplasy and that most of the observed incongruence was between $G S$ and $G 3 P D$ trees in the clade that included isolates from strawberry, citrus, and leatherleaf fern. The PHT was used to evaluate the null hypothesis that there is no history of recombination among lineages statistically. After nucleotide swapping between loci, the probability of obtaining a sum of tree lengths equal to or less than that observed was 0.001 when all loci and isolates were included in the analysis. When the ITS locus or sequence from blueberry isolates was excluded from the analysis, this probability did not change. The $P$ values for the PHT test indicate that the null hypothesis (i.e., there is no history of recombination among lineages) should be rejected.

Comparison of leatherleaf fern isolates from the United States and Costa Rica. The occurrence of dissimilar genotypes within the $G 3 P D$ and $G S$ regions of the three isolates initially characterized from Florida and the presence of multiple combinations of the G3PD and GS genotypes suggested that this population might be highly variable and evidence for recombination easily detected. The different G3PD genotypes could be distinguished from one another with the restriction enzyme RcaI and the $G S$ genotypes by the restriction enzyme Bst $\mathrm{UI}$. The three observed genotype combinations are referred to as GD-RcaI(-)/ GS-Bst UI(+), GD-RcaI(-)/GS-Bst UI(-), and GD-RcaI(+)/GS$B s t \mathrm{UI}(-)$. The $G 3 P D$ and $G S$ regions from five additional isolates from Florida were sequenced along with five isolates from different sites in Costa Rica. Costa Rican leatherleaf fern isolates were identical to one another, with the exception of a singlenucleotide polymorphism in the G3PD region, and only differed from isolate 05-161 from Florida by one nucleotide in the $G S$ region and either zero or one nucleotide in the $G 3 P D$ region (Fig. $2)$. These isolates were all GD-RcaI(+)/GS-Bst UI(-). No new genotypes were observed among the five additional Florida isolates from which sequence data were obtained. Restriction enzyme analysis of 26 additional isolates from Florida and 12 from Costa Rica did not reveal the presence of the fourth genotype, GD-RcaI(+)/GS-BstUI(+), that could occur by recombination of G3PD and $G S$ regions, even though isolates with both GD-RcaI and GS-Bst UI alleles were present at sampling sites in Florida (Table 7). Also, analysis of the additional 12 isolates from Costa Rica did not reveal the presence of the two other genotypes observed in Florida (Table 7).

\section{DISCUSSION}

Pathogenicity assays indicated that there are clear pathological differences between the genetically differentiable strains that explain the lack of migration of isolates between hosts to cause disease. Only isolates from group $\mathrm{C}$ and the recently described group A9 (44) have been isolated from blueberry. The present study indicates that isolates from Key lime, leatherleaf fern, PFDaffected citrus, and strawberry, from groups $\mathrm{J}$ and $\mathrm{D}$, lack the ability to infect fruit of this host. Only isolates from blueberry and strawberry infected strawberry fruit. The blueberry isolates in the present study were group $\mathrm{C}$ isolates that are commonly isolated from fruit of hosts such as peach, apple, pecan, and strawberry in addition to blueberry $(3,17,33)$. In fruit-rot assays, group $\mathrm{C}$ isolates from apple and peach produced lesions on a wide variety

\section{Glyceraldehyde-3-phosphate dehydrogenase $2^{\text {nd }}$ Intron}

\section{Glutamine synthetase $2^{\text {nd }}$ Intron}

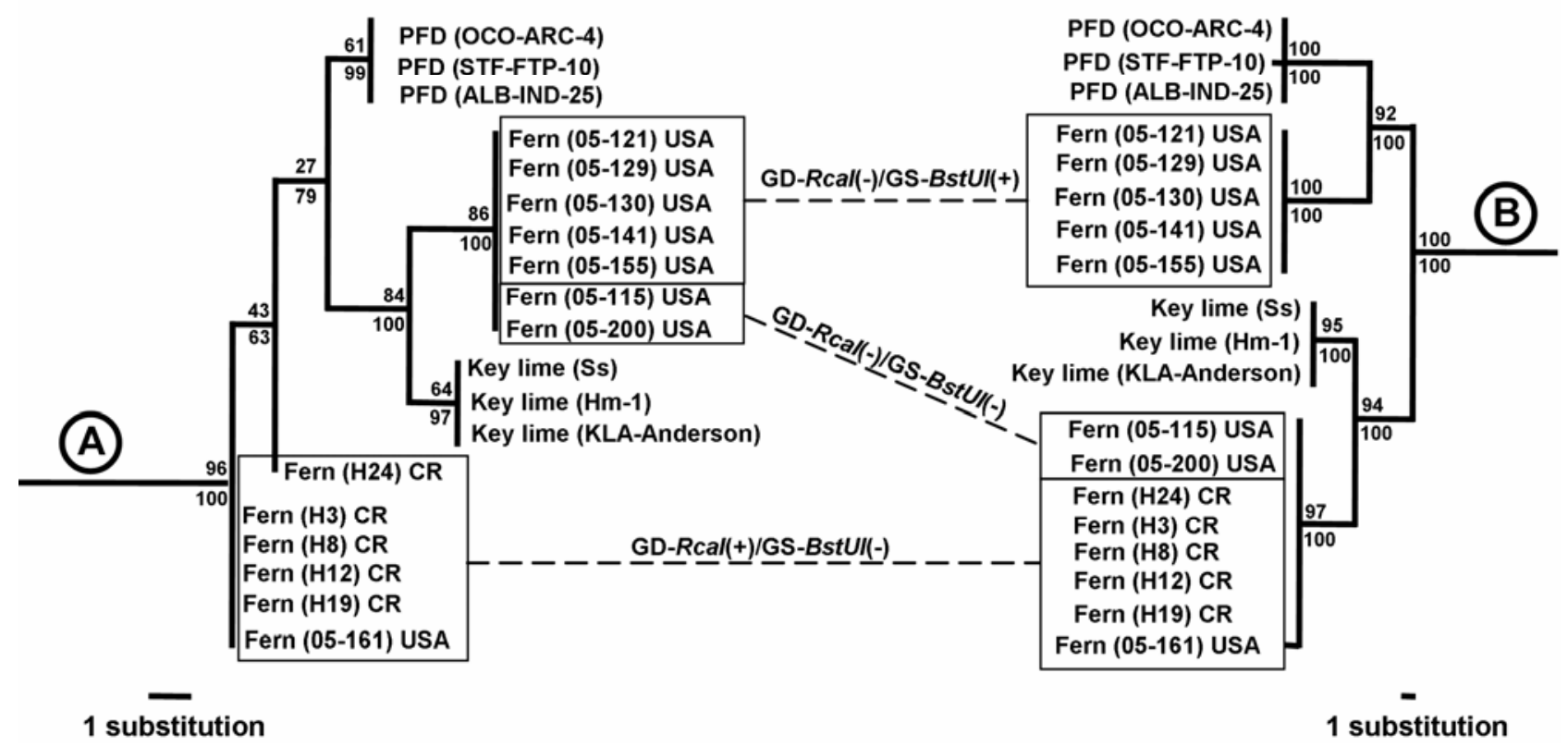

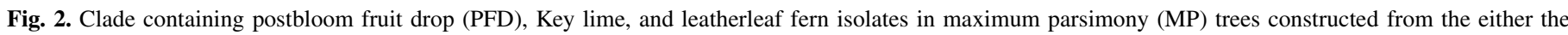

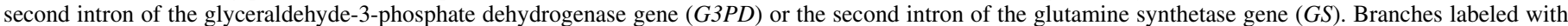

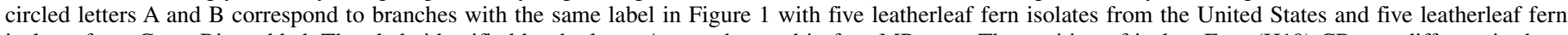

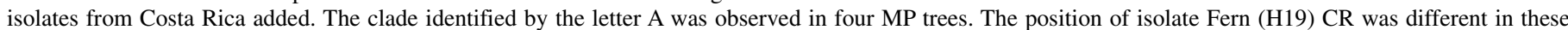

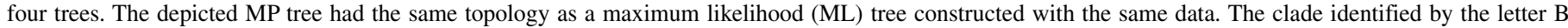

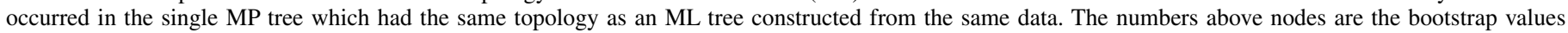

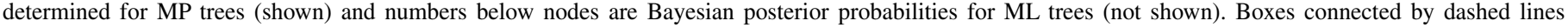

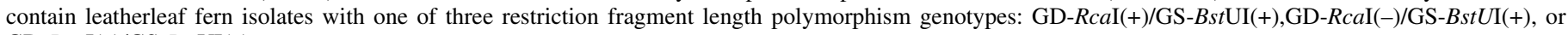
GD-RcaI(-)/GS-BstUI(-). 
of fruit (13), suggesting that isolates from this group have the ability to cross-infect fruit from multiple hosts. Group C contains at least some members of the CA-variable group on strawberry $(6,12,17,33)$, providing additional evidence that the blueberry isolates could cross-infect strawberry in Florida. However, isolates from the CA-variable group have not been found on strawberry in Florida (43). The incidence of strawberry fruit infected by blueberry isolates was lower and lesion size was smaller; therefore, the progression of an epidemic caused by a blueberry isolate would be slower than an epidemic caused by a CA-clonal isolate. Blueberry isolates also failed to cause disease on strawberry foliage and, therefore, epidemics might not be sustainable in the absence of fruit. Another possible explanation for the absence of the blueberry strain on strawberry in Florida is that the climate is unfavorable. C. acutatum does not appear to survive very well on blueberry fruit in Florida, where most of the ripe rot appears to be caused by $C$. gloeosporioides, but this is not the case in temperate regions further north (32).

On foliage of strawberry, Key lime, and leatherleaf fern, only homologous host isolates caused disease. These results suggest that the range of isolates capable of causing foliar diseases on these hosts is limited and they are consistent with previous studies examining the genetic relatedness of isolates from these hosts and cross-pathogenicity studies using some of these hosts. In one study, there was evidence for host differentiation among group $\mathrm{J}$ isolates obtained from PFD-affected citrus flowers, Key lime, and leatherleaf fern (17). PFD isolates have also been shown to either fail to produce disease or produce substantially less disease on Key lime $(1,25)$. A single genotype responsible for anthracnose on strawberry appears to have been distributed throughout most of the world, which suggests that strains able to reproduce on this host are few (6).

On Orlando tangelo flowers, isolates from four of five hosts caused PFD symptoms. However, the isolates from PFD-affected citrus were more aggressive. Consistent with the pathogenicity data, Key lime anthracnose isolates have been recovered from PFD-affected orange flowers in areas where this host is grown close to Key lime (25), and the ability of Key lime anthracnose isolates to infect citrus flowers and cause persistent calyx formation has been demonstrated (1). In addition to Key lime isolates, isolates from blueberry and strawberry produced flower lesions and increased the incidence of persistent calyxes relative to the control. These isolates, based on gene sequences, tended to be less similar to the PFD isolates than leatherleaf fern isolates which did not produce lesions on flowers. Even though isolates from other hosts cause PFD symptoms, isolates from PFDaffected flowers are exclusively PFD-type isolates, with the exception of KLA-type isolates near Key lime plantings (25). It may be that differences in aggressiveness between strains explain this phenomenon, although the ability of strains to survive between seasons on nonreproductive tissue might also be a contributing factor.
A teleomorph has been associated with only group C, F, and J4 isolates $(17,21)$, which includes only the blueberry isolates from the present study. It is presumed that the mode of reproduction for other groups is vegetative. The results of the PHT indicated that, although these other groups may reproduce vegetatively, there is evidence for recombination. More tangible evidence for recombination came from the genotypes observed for leatherleaf fern isolates. The $G 3 P D$ and $G S$ sequences occurred in three as opposed to two combinations. Neither of the two divergent G3PD and $G S$ sequences within the leatherleaf fern population grouped together into a clade that did not include an isolate from at least one other host, which excludes the possibility that different rates of evolution within clonal lineages accounted for the different genotypes. The absence of a fourth potential combination suggests that recombination is not a frequent event, which is consistent with the absence of any descriptions of a teleomorph produced from group $\mathrm{J}$ isolates. Both G3PD and GS sequences co-occurred at two sites; thus, geographic separation of the different strains cannot account for the absence of this fourth genotype. The lack of homoplasy in trees constructed from individual loci also suggests that recombination is not frequent. The different position occupied by the strawberry isolates relative to the group $\mathrm{J}$ isolates in the tree constructed from the ITS region also indicates that recombination might occur between more distantly related strains than the group $\mathrm{J}$ isolates.

The $\beta$-tubulin- 2 gene, the ITS region, the G3PD second intron, and the $G S$ second intron have all been used by others to identify groups within $C$. acutatum $(17,33,44)$. Generally, isolate groups determined from gene trees for each genomic region contain the same set of isolates; however, the relationship between some isolate groups differs. Trees reported in the literature from all four regions were in good agreement with the trees generated from the Florida sample in that group $\mathrm{D}$ and $\mathrm{J}$ isolates consistently form a clade with group $\mathrm{C}$ isolates as an outgroup. Conflicts in the reported trees occur with respect to the position of $\mathrm{J} 4$ and $\mathrm{F}$ isolates, two groups that were not found in the Florida sample. Recombination among groups might account for the differences.

It has been suggested that the $C$. acutatum strains responsible for anthracnose of leatherleaf fern in Florida were imported into the state from Costa Rica, where the disease first appeared (24). However, this hypothesis was not supported by the observation that only one of three leatherleaf fern genotypes present in Florida was present among isolates from Costa Rica. In a previous study, based on universally primed (UP)-PCR fingerprints, there were 10 different $C$. acutatum genotypes on leatherleaf fern in Costa Rica within a sample population of 40 isolates at four sites. This indicates that there is genetic variation within the Costa Rican population and that this variation might be reflected in sequences from the $G 3 P D$ and $G S$ regions (30). Possibly, the Costa Rica sample that was compared with the Florida sample was not large enough to detect all three genotypes observed in Florida. However, the sample contained 17 isolates from five sites and should

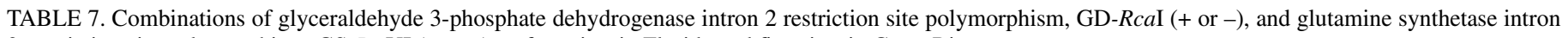
2 restriction site polymorphism, GS-Bst UI (+ or -), at four sites in Florida and five sites in Costa Rica

\begin{tabular}{|c|c|c|c|c|c|}
\hline Site & No. of isolates & GD-RcaI(+) GS-Bst $\mathrm{UI}(+)$ & GD-RcaI(+) GS-BstUI(-) & GD-RcaI(-) GS-BstUI(+) & GD-RcaI(-) GS-Bst $\mathrm{UI}(-)$ \\
\hline Crescent City, FL, USA & 14 & 0 & 9 & 5 & 0 \\
\hline Pierson, FL, USA (FJ) & 5 & 0 & 1 & 4 & 0 \\
\hline Pierson, FL, USA (VP) & 5 & 0 & 0 & 5 & 0 \\
\hline Florida combined & 34 & 0 & 10 & 14 & 10 \\
\hline Fraijanes, Alajuela, Costa Rica & 3 & 0 & 3 & 0 & 0 \\
\hline San Pablo, Alajuela, Costa Rica & 3 & 0 & 3 & 0 & 0 \\
\hline Cervantes, Cartago, Costa Rica & 2 & 0 & 2 & 0 & 0 \\
\hline Costa Rica combined & 17 & 0 & 17 & 0 & 0 \\
\hline All sites combined & 51 & 0 & 27 & 14 & 10 \\
\hline
\end{tabular}


have identified a large proportion of the variance observed in the prior study. In addition, in the prior study, the genetic distances between leatherleaf fern isolates were much less than the distances between leatherleaf fern isolates and a group J citrus isolate (30), whereas the distances between leatherleaf fern isolates in Florida based on G3PD and GS sequences were as large as the distances between PFD and leatherleaf fern isolates. Together, these observations suggest that it is unlikely that the described variation in UP-PCR fingerprints correlates with variation in the $G 3 P D$ and $G S$ introns observed among Florida isolates. A second possible explanation for the unique genotypes in Florida is that they resulted from two hybridization events with another strain after importation. If this were true, then Costa Rican isolates should occupy the same position within the trees constructed from both $G 3 P D$ and $G S$ regions, but this was not the case because only GD-RcaI(-)/GS-BstUI(-) genotype isolates from Florida occupied a consistent position in both trees. A third explanation, consistent with the data, is that anthracnose on leatherleaf fern in Costa Rica was imported from Florida, or a third location was the source of strains present in Florida and Costa Rica. It is also worth noting that the ITS sequence from fern isolates was identical to that of Colletotrichum spp. isolated from wax apple, papaya, mango, and pepper in Taiwan and Thailand (39; deposited without published reference) (GenBank accession nos. DQ454012, EF608061, EF608055, and EF608052). This suggests that $C$. acutatum strains from leatherleaf fern might cause disease on a more taxonomically diverse group of plants, but none of these plant species were included in the present study.

In conclusion, $C$. acutatum isolates from anthracnose-affected Key lime, strawberry, and leatherleaf fern; citrus with PFD symptoms; and ripe-rot-affected blueberry in Florida were genetically distinct from one another and isolates were more pathogenic or the only pathogen on hosts or tissue from which they were isolated. The group designations of the isolates were consistent with those for isolates from these hosts described in other studies, indicating that the group designations provide information that could be used to predict the pathogenicity of isolates. However, within genetic groups, strains may still display host preference as demonstrated for group $\mathbf{J}$ isolates from leatherleaf fern, PFDaffected citrus, and Key lime. Results of pathogenicity tests also suggest that senescing tissues, such as flower petals and fruit, are more likely to be infected by genetically divergent strains than physiologically active leaf tissue. Although no teleomorph has been reported for the $C$. acutatum strains isolated from fern, strawberry, and citrus in the state, there was evidence for historical recombination among these isolates. Although there is no clear mechanism by which this recombination might occur, it suggests a way in which novel $C$. acutatum genotypes can be produced from lineages with no apparent sexual stage.

\section{LITERATURE CITED}

1. Agostini, J. P., Timmer, L. W., and Mitchell, D. J. 1992. Morphological and pathological characteristics of strains of Colletotrichum gloeosporioides from citrus. Phytopathology 82:1377-1382.

2. Barker, F. K., and Lutzoni, F. M. 2002. The utility of the incongruence length difference test. Syst. Biol. 51:625-637.

3. Bernstein, B., Zehr, E. I., Dean, R. A., and Shabi, E. 1995. Characteristics of Colletotrichum from peach, apple, pecan, and other hosts. Plant Dis. 79:478-482.

4. Brown, A. E., Sreenivasaprasad, S., and Timmer, L. W. 1996. Molecular characterization of slow-growing orange and key lime anthracnose strains of Colletotrichum from citrus as C. acutatum. Phytopathology 86:523527.

5. Denoyes, B., and Baudry, A. 1995. Species identification and pathogenicity study of French Colletotrichum strains isolated from strawberry using morphological and cultural characteristics. Phytopathology 85:5357.

6. Denoyes-Rothan, B., Guerin, G., Délye, C., Smith, B., Minz, D., Maymon, M., and Freeman, S. 2003. Genetic diversity and pathogenic variability among isolates of Colletotrichum species from strawberry.
Phytopathology 93:219-228.

7. Denoyes-Rothan, B., Lafargue, M., Guerin, G., and Clerjeau, M. 1999. Fruit resistance to Colletotrichum acutatum in strawberries. Plant Dis. 83:549-553.

8. Dolphin, K., Belshaw, R., Orme, C. D. L., and Quicke, D. L. J. 2000. Noise and incongruence: Interpreting results of the incongruence length difference test. Mol. Phylogenet. Evol. 17:401-406.

9. Du, M. Z., Schardl, C. L., Nuckles, E. M., and Vaillancourt, E. M. 2005. Using mating-type gene sequences for improved phylogenetic resolution of Colletotrichum species complexes. Mycologia 97:641-658.

10. Felsenstein, J. 1981. Evolutionary trees from DNA sequences: a maximum likelihood approach. J. Mol. Evol. 17:368-376.

11. Freeman, S., and Katan, T. 1997. Identification of Colletotrichum species responsible for anthracnose and root necrosis of strawberry in Israel. Phytopathology 87:516-521.

12. Freeman, S., Minz, D., Maymon, M., and Zveibil, A. 2001. Genetic diversity within Colletotrichum acutatum sensu Simmonds. Phytopathology 91:586-592.

13. Freeman, S., and Shabi, E. 1996. Cross-infection of subtropical and temperate fruits by Colletotrichum species from various hosts. Physiol. Mol. Plant Pathol. 49:395-404.

14. Freeman, S., Shabi, E., and Katan, T. 2000. Characterization of Colletotrichum acutatum causing anthracnose of anemone (Anemone coronaria L.). Appl. Environ. Microbiol. 66:5267-5272.

15. Geiser, D. M., Pitt, J. I., and Taylor, J. W. 1998. Cryptic speciation and recombination in the aflatoxin-producing fungus Aspergillus flavus. Proc. Natl. Acad. Sci. USA 95:388-393.

16. Guerber, J. C., and Correll, J. C. 2001. Characterization of Glomerella acutata, the teleomorph of Colletotrichum acutatum. Mycologia 93:216229.

17. Guerber, J. C., Liu, B., Correll, J. C., and Johnston, P. R. 2003. Characterization of diversity in Colletotrichum acutatum sensu lato by sequence analysis of two gene introns, mtDNA and intron RFLPs, and mating compatibility. Mycologia 95:872-895.

18. Hasegawa, M., Kishino, H., and Yano, T. 1985. Dating of the human-ape splitting by a molecular clock of mitochondrial DNA. J. Mol. Evol. 22:160-174.

19. Howard, C. M., Maas, J. L., Chandler, C. K., and Albregts, E. E. 1992. Anthracnose of strawberry caused by the Colletotrichum complex in Florida. Plant Dis.76:976-981.

20. Kimura, M. 1980. A simple method for estimating evolutionary rates of base substitutions through comparative studies of nucleotide sequences. J. Mol. Evol. 16:111-120.

21. Lardner, R., Johnston, P. R., Plummer, K. M., and Pearson, M. N. 1999. Morphological and molecular analysis of Colletotrichum acutatum sensu lato. Mycol. Res. 103:275-285.

22. Liu, B., Wasilwa, T. E., Morelock, T. E., O'Neill, N. R., and Correll, J. C. 2007. Comparison of Colletotrichum orbiculare and several allied Colletotrichum spp. for mtDNA RFLPs, intron RFLP and sequence variation, vegetative compatibility, and host specificity. Phytopathology 97:1305-1314.

23. Nirenberg, H. I., Feiler, U., and Hagendorn, G. 2002. Description of Colletotrichum lupini comb. nov. in modern terms. Mycologia 94:307320 .

24. Norman, D. J., and Strandberg, J. O. 1997. Survival of Colletotrichum acutatum in soil and plant debris of leatherleaf fern. Plant Dis. 81:11771180.

25. Peres, N. A., MacKenzie, S. J., Peever, T. L., and Timmer, L. W. 2008. Postbloom fruit drop of citrus and Key lime anthracnose are caused by distinct phylogenetic lineages of Colletotrichum acutatum. Phytopathology 98:345-352.

26. Peres, N. A., Timmer, L. W., Adaskaveg, J. E., and Correll, J. C. 2005. Lifestyles of Colletotrichum acutatum. Plant Dis. 89:784-796.

27. Polashock, J. J., Ehlenfeldt, M. K., Stretch, A. W., and Kramer, M. 2005. Anthracnose fruit rot resistance in blueberry cultivars. Plant Dis. 89:3338.

28. Posada, D., and Crandall, K. A. 1998. MODELTEST: Testing the model of DNA substitution. Bioinformatics 14:817-818.

29. Ronquist, F., and Heulsenbeck, J. P. 2003. MrBayes 3: Baysian phylogenetic inference under mixed models. Bioinformatics 19:1572-1574.

30. Schiller, M., Lubeck, M., Sundelin, T., Meléndez, L. F. C., Danielsen, S., Jensen, D. F., and Ordeñana, K. M. 2006. Two populations of Colletotrichum acutatum are responsible for anthracnose in strawberry and leatherleaf fern in Costa Rica. Eur. J. Plant Pathol. 116:107-118.

31. Simmonds, J. H. 1965. A study of the species of Colletotrichum causing fruit rots in Queensland. Queensl. J. Agric. Anim. Sci. 22:437-459.

32. Smith, B. J., Magee, J. B., and Gupton, C. L. 1996. Susceptibility of rabbiteye blueberry cultivars to postharvest diseases. Plant Dis. 80:215-218.

33. Sreenivasaprasad, S., and Talhinhas, P. 2005. Genotypic and phenotypic diversity in Colletotrichum acutatum, a cosmopolitan pathogen causing 
anthracnose on a wide range of hosts. Mol. Plant. Pathol. 6:361-378.

34. Stamps, R. H., Strandberg, J. O., and Norman, D. J. 1997. Incidence, severity and control of anthracnose in leatherleaf fern in Florida. Proc. Fla. State Hortic. Soc. 110:115-118.

35. Stephenson, S. A., Green, J. R., Manners, J. M., and Maclean, D. J. 1997. Cloning and characterization of glutamine synthetase from Colletotrichum gloeosporioides and demonstration of elevated expression during pathogenesis on Stylosanthes guianensis. Curr. Genet. 31:447-454.

36. Talhinhas, P., Sreenivasaprasad, S., Neves-Martins, J., and Oliveira, H. 2002. Genetic and morphological characterization of $C$. acutatum causing anthracnose of lupins. Phytopathology 92:986-996.

37. Talhinhas, P., Sreenivasaprasad, S., Neves-Martins, J., and Oliveira, H. 2005. Molecular and phenotypic analyses reveal association of diverse Colletotrichum acutatum groups and a low level of C. gloeosporioides with olive anthracnose. Appl. Environ. Microbiol. 71:2987-2998.

38. Templeton, M. D., Rikkerink, E. H., Solon, S. L., and Crowhurst, R. N. 1992. Cloning and molecular characterization of the glyceraldehyde-3phosphate dehydrogenase-encoding gene and cDNA from the plant pathogenic fungus Glomerella cingulata. Gene 122:225-230.

39. Than, P. P, Jeewon, R., Hyde, K. D., Pongeupasamit, S., Mongkolporn, O., and Taylor, P. W. J. 2008. Characterization and pathogenicity of Colletotrichum species associated with chili (Capsicum spp.) in Thailand. Plant Pathol. 57:562-572.

40. Than, P. P., Shivas, R. G., Jeewon, R., Pongeuasamit, S., Marney, T. S.,
Taylor, P. W. J., and Hyde, K. D. 2008. Epitypification and phylogeny of Colletotrichum acutatum J.H. Simmonds. Fungal Diversity 28:97-108.

41. Thompson, J. D., Higgins, D. G., and Gibson, T. J. 1994. CLUSTAL W: Improving the sensitivity of progressive multiple sequence alignment through sequence weighting, position-specific gap penalties and weight matrix choice. Nucleic Acids Res. 22:4673-4680.

42. Timmer, L. W., Agostini, J. P., Zitko, S. E., and Zulfiqar, M. 1994. Postbloom fruit drop of citrus, an increasingly prevalent disease of citrus in the Americas. Plant Dis. 78:329-334.

43. Ureña-Padilla, A. R., MacKenzie, S. J., Brown, B. W., and Legard, D. E. 2002. Etiology and population genetics of Colletotrichum spp. causing crown and fruit rot of strawberry. Phytopathology 92: 1245-1252.

44. Whitelaw-Weckert, M. A., Curtin, S. J., Humg, R., Steel, C. C., Blanchard, C. L., and Roffey, P. E. 2007. Phylogenetic relationships and pathogenicity of Colletotrichum acutatum isolates from grape in subtropical Australia. Plant Pathol. 56:448-463.

45. White, T. J., Bruns, T., Lee, S., and Taylor, J. 1990. Amplification and direct sequencing of fungal ribosomal RNA genes for phylogenetics. Pages 315-322 in: PCR Protocols: A Guide to Methods and Application. M. A. Innis, D. H. Gelfand. J. J. Sninsky, and T. J. White, eds. Academic Press, San Diego, CA.

46. Xiao, C. L., MacKenzie, S. J., and Legard, D. E. 2004. Genetic and pathogenic analysis of Colletotrichum gloeosporioides isolates from strawberry and noncultivated hosts. Phytopathology 94:446-453. 